\title{
Design and Methods of the Korean National Investigations of 70,000 Suicide Victims Through Police Records (The KNIGHTS Study)
}

\author{
Eun Jin $\mathrm{Na}^{1,2}$, Jinhwa Choi ${ }^{1}$, Dajung Kim¹, Heeyoun Kwon', Yejin Lee', Gusang Lee', \\ Maurizio Fava ${ }^{3}$, David Mischoulon ${ }^{3}$, Jihoon Jang ${ }^{1,2}$, and Hong Jin Jeon ${ }^{1,2,4} \bowtie$ \\ ${ }^{1}$ Korea Psychological Autopsy Center (KPAC), Seoul, Republic of Korea \\ 2Department of Psychiatry, Depression Center, Samsung Medical Center, Sungkyunkwan University School of Medicine, Seoul, Republic of Korea \\ ${ }^{3}$ Depression Clinical and Research Program, Massachusetts General Hospital, Harvard Medical School, Boston, USA \\ ${ }^{4}$ Department of Health Sciences \& Technology, Department of Medical Device Management \& Research, and Department of Clinical Research Design \\ \& Evaluation, Samsung Advanced Institute for Health Sciences \& Technology (SAIHST), Sungkyunkwan University, Seoul, Republic of Korea
}

Objective The suicide rate in South Korea was the second highest among the Organization for Economic Cooperation and Development countries in 2017. The purpose of this study is to understand the characteristics of people who died by suicide in Korea from 20132017 and to better prevent suicide.

Methods This study was performed by the Korea Psychological Autopsy Center (KPAC), an affiliate of the Korea Ministry of Health and Welfare. According to the Korea National Statistical Office, the number of suicide victims nationwide was estimated to reach about 70,000 from 2013 to 2017. Comprehensive suicide records from all 254 police stations in South Korea were evaluated by 32 investigators who completed a 14-day didactic training program. Then, we evaluated the characteristics of suicide victims in association with disease data from the National Health Insurance Database (NHID), which is anonymously linked to personal information of suicide victims.

Results Thirty-one of 254 police stations in the Seoul metropolitan area were analyzed by August 10, 2018. Findings showed that the characteristics of suicide victims differed according to the nature of the region.

Conclusion Our results suggest that different strategies and methods are needed to prevent suicide by regional groups.

Psychiatry Investig 2019;16(10):777-788

Key Words Suicide, Police investigation record, South Korea, Region.

\section{INTRODUCTION}

The annual suicide rate in South Korea has been the highest among the Organization for Economic Cooperation and Development countries for the last decade. The annual agestandardized suicide rate in South Korea has gradually increased from 25.1 per 100,000 people in 2005 to 29.1.0 per 100,000 people in 2011. ${ }^{1}$ The South Korean government enacted a law (The Act on the Prevention of Suicide and the De-

\footnotetext{
Received: May 13, 2019 Accepted: July 14, 2019

$\square$ Correspondence: Hong Jin Jeon, MD, PhD

Department of Psychiatry, Depression Center, Samsung Medical Center, Sungkyunkwan University School of Medicine, 81 Irwon-ro, Gangnam-gu, Seoul 06351, Republic of Korea

Tel: +82-2-3410-3586, Fax: +82-2-3410-0050, E-mail: jeonhj@skku.edu

(a) This is an Open Access article distributed under the terms of the Creative Commons Attribution Non-Commercial License (https://creativecommons.org/licenses/bync/4.0) which permits unrestricted non-commercial use, distribution, and reproduction in any medium, provided the original work is properly cited.
}

velopment of a Life-Savings Culture) in $2012^{2}$ aiming to reduce the ever-increasing suicide rate. Suicide rates have declined slightly since the legislation, but South Korea is still at the top of the list, second only to Lithuania, which was incorporated into the OECD countries in 2018. Therefore, new efforts to reduce suicide in South Korea are sorely needed.

To prevent suicide, the first step is to determine the cause. However, this is not an easy task, as there are many reasons for which individuals may commit suicide. Moreover, suicide is not caused by a single factor but by a combination of various factors. According to Hawton and Saunders, ${ }^{3}$ multi-factorial causes of suicide are divided into the following: state-dependent or trait-dependent factors, and distal or proximal factors. A detailed analysis of the causes of suicide is needed to develop appropriate measures to prevent suicide. Furthermore, there has recently been an increasing awareness of the importance of evidence-based suicide prevention policies. ${ }^{4-7}$ Previ- 
ous studies on evidence-based suicide prevention strategies ${ }^{8-10}$ have revealed that different approaches are needed at the individual level and at the social level to prevent suicide.

Similarly to other countries, South Korea has many causes of suicide. A number of research studies ${ }^{11-16}$ have examined causes of the high suicide rate in South Korea. In addition, a variety of suicide prevention policies are being implemented. However, rather than implementing evidence-based prevention policies by region, general preventive policies based on common causes of suicide are being put into action. For example, the Regional Mental Health Promotion Center, an affiliated organization of the Ministry of Health and Welfare, has polices to prevent suicide, but they do not reflect the nature of particular regions and the characteristics of suicide death in those regions. Therefore, policies implemented throughout the specific region are almost identical. In South Korea, districts have various regional characteristics. However, there is a lack of research on regional characteristics to implement preventive policies suitable for each region in South Korea. Thus, it is important to know the characteristics of each region, so as to implement policies suitable for the region to reduce suicide rates.

Few research studies have examined regional differences in suicides in South Korea. Most studies ${ }^{17-27}$ have examined only the various risk factors and associations of individuals with specific diseases in South Korea. There has been one report on the topic ${ }^{28}$ but it only concluded that there were differences in regions and did not study the regional characteristics in detail. In order to find new ways to solve this problem, it is first necessary to analyze the nature of suicides by region.

In accordance with this view, the South Korean government started the Suicide Prevention Action Plan in 2018 to study regional differences between suicide victims. The purpose of this study is as follows: 1) to examine the regional characteristics of suicide victims in South Korea in detail, 2) to enforce evidence-based suicide prevention policies based on regional differences, and 3) to reduce the high suicide rate in South Korea.

\section{METHODS}

\section{Pilot study}

The Korea Psychological Autopsy Center conducted a pilot study that examined suicide victims in seven districts over two years, from 2016 to 2017. Before the pilot study, we reviewed the law with legal experts to prevent possible problems related to personal information in study and went through prior consultation with the National Police Agency and regional police station to examine data on all suicide victims officially recorded in police investigation records. In order to examine the characteristics of suicide victims in each region, we selected districts that had unique characteristics of urban and rural areas. After this examination, we proved the validity and the necessity of this study that will be the cornerstone of local suicide prevention.

\section{Process of investigation}

\section{Preparation of investigation}

The South Korean government decided to expand its study on the characteristics of suicide victims by region across the country as one of the Suicide Prevention Action Plans in 2018. We organized an advisory committee, including experts from different fields (psychiatry, social welfare, statistics, law and public office) to examine the causes of suicide from a more diverse perspective. We held several meetings with the advisory committee to discuss the examination content, methods of analysis and interpretation of data based on the preliminary findings during the pilot study. We checked for errors and amendments confirmed through the pilot study in seven districts over two years. We proceeded with the research process in two sequential steps for a more in-depth investigation and analysis. First, we collected and analyzed more accurate data on personal information (ID number, age, sex and so on), locations, methods and main causes of suicide victims through police investigation records from 2013 to 2017. Second, we studied characteristics of suicide victims in association with disease data from the National Health Insurance Database (NHID), which is anonymously linked to the personal information (ID number, especially to identify an individual) of suicide victims. Because Korean health insurance is provided by the government through a universal health insurance system, every citizen is obligatorily inducted into the Korea National Health Insurance in their lifetime without exception.

\section{Study population and districts}

The study was performed by the Korea Psychological Autopsy Center, an affiliate of the Korea Ministry of Health and Welfare operated by the Sungkyunkwan University Research and Business Foundation. We made a plan to execute complete enumeration for examining all suicide victims during a five-year span, from 2013 to 2017, that were officially recorded in police investigation records in South Korea. The data examination for this study will be conducted from May 2018 to December 2019. This study was approved by the Institutional Review Board (IRB) of Samsung Medical Center. Informed consent was waived by IRB because we obtained data of deceased persons, therefore not violating the Personal Information Protection Act (SMC 2019-01-097).

South Korea is divided into 17 regions (1 Seoul metropolitan government; 1 autonomous city; 6 metropolitan cities; 9 
provinces) according to administrative districts, and the 17 regions have 254 police stations in total. All 254 police stations in the 17 regions were included in the examination. According to the Korea National Statistical Office, the number of suicide victims nationwide was estimated to reach about 70,000 from 2013 to 2017. Among the 17 regions, the examination of 8 regions was completed in December 2018, and the examination for the rest of the regions is planned for next year, from January 2019 to December 2019 (Figure 1).

\section{Selecting and educating investigators}

A total of 32 investigators were recruited nationwide in May 2018, including mental health professionals: certified psychiatric and mental health nurses, mental health psychologists, and mental health social workers with experience in psychiatric epidemiologic surveys. All investigators received a 14-day training with didactic sessions including psychopathology related to suicide, understanding the examination items, and practical training for the examination. The practical training was utilized to facilitate acquisition of new knowledge of the examination. and group discussions were used to check interrater reliability. Furthermore, stress workshops were conduct- ed twice before the investigation to prevent indirect and direct trauma that might occur during the investigation because the police investigation records include not only the details of suicide but also various photo data related to suicide. Also, our research team established regulations that one could receive treatment and emotional support related to trauma at any time if an unexpected direct or indirect trauma occurred during the investigation.

\section{Measurement of examination}

According to Edwin S. Shneidman, the original creator of the term psychological autopsy (PA), PA means to clarify an equivocal death and to arrive at the correct or accurate mode of that death. The Korea Psychological Autopsy Center ${ }^{29}$ was established in 2014 for the examination of suicide victims and to support suicide survivors. It created the Korea-Psychological Autopsy Checklist (K-PAC), which we used to develop the Korea-Psychological Autopsy Checklist for Police Records (KPAC-PR 1.0). We consulted with the advisory committee to correct and supplement this checklist based on K-PAC, which identifies the cause of death of suicide victims in the Korea Psychological Autopsy Center. In the first step, the examination



Figure 1. Study sample and investigation regions. 
items are as follows: basic personal information on suicide victims, information related to the suicide, information on the suicide causes; and information from the statements of the persons concerned (Table 1). In the next step, the examination considers any mental and physical disorders of suicide victims with data from the National Health Insurance Database (NHID). NHID is based on claims data containing all citizens' demographics such as sex, age [in 5-year units], economic status [income distribution], disability, and healthcare utilization.

We developed a tool to examine the characteristics of suicide victims in police investigation records and made an electronic Case Report Form (eCRF) with the Korea Centers for Disease Control and Prevention (KCDC) for minimizing errors and increasing accuracy in collecting the data of suicide victims.

\section{Statistical analysis}

Depending on the type of examination of the characteristics of the suicide victims, it was necessary to vary our methods of analysis accordingly. We sought to perform a descriptive analysis of the personal information of the suicide victims and the information related to the suicide, and to carry out a nested case-control study for the analysis of suicide victims with psychiatric and physical disorders.

For the descriptive analysis, we calculated the absolute number of nationwide suicide victims by 17 regions based on this study and the rate of suicide per cause by regional group in the total study population and in subgroups stratified by sex and age ( $<19$ years, $20-34$ years, $35-49$ years, $50-65$ years, and $>65$ years). Next, we analyzed differences in locations, methods and main causes of suicide according to the age and sex of suicide victims.

To investigate whether the medical conditions of suicide victims were related to suicide, it was necessary to compare suicide victims versus the general population. In a retrospective study, a nested case-control design was appropriate to compare psychiatric and physical disorders of suicide victims versus the general population. To determine whether the risk of suicide was increased with selected psychiatric and physical disorders, odds ratios (ORs) and two-tailed 95\% confidence intervals were estimated using conditional logistic regression models for matched case-control pairs. Crude models were inherently adjusted for sex and age by the study design with each disorder as exposure. In adjusted models, we included economic status (four categories), disability, and all psychiatric and physical disorders. To examine whether the effect of the disorder on the risk of suicide differed by sex and age, the same analysis was conducted for subgroups stratified by sex and age groups. All statistical analyses were performed with SAS version 9.4 (SAS Institute, Cary, NC, USA).

\section{RESULTS}

The results of this study are based on the data investigated until the end of 2018. We investigated suicide victims distributed among 31 police stations in the city of Seoul city and analyzed the characteristics of suicide victims in 25 districts. This report presents the framework of the analysis that we will continue until 2020 and shows the unique District A, which has somewhat different characteristics of suicide victims than Seoul. The study will continue to investigate 254 police stations until the end of December 2019. The analysis will be conducted in 229 regions, and reports from these regions will be provided to those responsible for local health care.

\section{Demographic profiles of suicide victims by regional group}

Table 2 describes the number of suicide victims and the demographic characteristics [sex, age, elderly (>65), marital status, solitary condition and employment status] of suicide victims in District A of Seoul from 2013-2017. It shows the yearby-year changes in the number of suicide victims in District $A$ and their demographic characteristics, compared to all of Seoul. Therefore, Table 2 can help to better explain the characteristics

Table 1. Investigation factors list

\begin{tabular}{lc}
\hline \multicolumn{1}{c}{ Investigation factor } & \multicolumn{1}{c}{ Detailed factors } \\
\hline Demographic characteristics & $\begin{array}{c}\text { Name, Gender, Resident registration-based address, Actual residence address, Place of residence } \\
\text { category, Education status, Employment status, Occupation, Marital status, Existence of cohabitant, } \\
\text { Detail information of cohabitant, etc. }\end{array}$ \\
Information related to the suicide & $\begin{array}{c}\text { Date of suicide, Date of Finding, Time of Finding, Estimated-time of death, Categories of location } \\
\text { where found, First finder, Method of suicide, etc. }\end{array}$ \\
Information on the causes of suicide & $\begin{array}{l}\text { Occupational Problem, Economic Problem, Family-related problem, Interpersonal problem, } \\
\text { Physical health problem, Mental health problem, Symptoms of mental health problem, Estimated } \\
\text { Informants' interview information }\end{array}$ \\
& mental illness, History of psychiatric diagnosis or treatment, etc. \\
& Relationship with the victim, Changes in the victim before death, warning signs: verbal, behavioral, \\
&
\end{tabular}


of suicide victims in District A.

Locations, methods and causes of suicide victims

Table 3 describes the locations, methods and main causes of suicide victims in District A of Seoul from 2013-2017. This table also represents specific information related to suicide and how different District A is from Seoul. In particular, District A has different features related to suicide method compared to

Table 2. Demographic profiles of suicide victims in District $A$

\begin{tabular}{|c|c|c|c|c|c|c|c|}
\hline & \multicolumn{6}{|c|}{ District A } & \multirow{2}{*}{$\frac{\text { Seoul }}{\text { Total of Seou }}$} \\
\hline & 2013 & 2014 & 2015 & 2016 & 2017 & $\begin{array}{r}\text { Total of } \\
\text { district A }\end{array}$ & \\
\hline Number & $133(100 \%)$ & $136(100 \%)$ & $108(100 \%)$ & $108(100 \%)$ & $87(100 \%)$ & $572(100 \%)$ & $9,893(100 \%)$ \\
\hline \multicolumn{8}{|l|}{ Sex } \\
\hline Male & $65(48.9 \%)$ & $78(57.4 \%)$ & $46(42.6 \%)$ & $62(57.4 \%)$ & $59(67.8 \%)$ & $310(54.2 \%)$ & $6,629(67.0 \%)$ \\
\hline Female & $68(51.1 \%)$ & $58(42.6 \%)$ & $62(57.4 \%)$ & $46(42.6 \%)$ & $28(32.2 \%)$ & $262(45.8 \%)$ & $3,262(33.0 \%)$ \\
\hline Unknown & $0(0.0 \%)$ & $0(0.0 \%)$ & $0(0.0 \%)$ & $0(0.0 \%)$ & $0(0.0 \%)$ & $0(0.0 \%)$ & $2(0.0 \%)$ \\
\hline Total & $133(100 \%)$ & $136(100 \%)$ & $108(100 \%)$ & $108(100 \%)$ & $87(100 \%)$ & $572(100 \%)$ & $9,893(100 \%)$ \\
\hline \multicolumn{8}{|l|}{ Age } \\
\hline Under 10's & $2(1.5 \%)$ & $6(4.4 \%)$ & $3(2.8 \%)$ & $6(5.6 \%)$ & $1(1.1 \%)$ & $18(3.1 \%)$ & $248(2.5 \%)$ \\
\hline 20 's & $22(16.5 \%)$ & $26(19.1 \%)$ & $20(18.5 \%)$ & $23(21.3 \%)$ & $10(11.5 \%)$ & $101(17.7 \%)$ & $1,086(11.0 \%)$ \\
\hline 30 's & $46(34.6 \%)$ & $40(29.4 \%)$ & $32(29.6 \%)$ & $24(22.2 \%)$ & $30(34.5 \%)$ & $172(30.1 \%)$ & $1,628(16.5 \%)$ \\
\hline 40 's & $20(15.0 \%)$ & $18(13.2 \%)$ & $20(18.5 \%)$ & $20(18.5 \%)$ & $20(23.0 \%)$ & $98(17.1 \%)$ & $1,788(18.1 \%)$ \\
\hline 50 's & $23(17.3 \%)$ & $21(15.4 \%)$ & $13(12.0 \%)$ & $15(13.9 \%)$ & $11(12.6 \%)$ & $83(14.5 \%)$ & $1,912(19.3 \%)$ \\
\hline 60 's & $8(6.0 \%)$ & $15(11.0 \%)$ & $7(6.5 \%)$ & $13(12.0 \%)$ & $7(8.0 \%)$ & $50(8.7 \%)$ & $1,263(12.8 \%)$ \\
\hline 80 's & $9(6.8 \%)$ & $7(5.1 \%)$ & $5(4.6 \%)$ & $4(3.7 \%)$ & $2(2.3 \%)$ & $27(4.7 \%)$ & $1,291(13.0 \%)$ \\
\hline 80 's & $2(1.5 \%)$ & $1(0.7 \%)$ & $8(7.4 \%)$ & $1(0.9 \%)$ & $5(5.7 \%)$ & $17(3.0 \%)$ & $559(5.7 \%)$ \\
\hline Over 90's & $1(0.8 \%)$ & $2(1.5 \%)$ & $0(0.0 \%)$ & $2(1.9 \%)$ & $1(1.1 \%)$ & $6(1.0 \%)$ & $113(1.1 \%)$ \\
\hline Unknown & $0(0.0 \%)$ & $0(0.0 \%)$ & $0(0.0 \%)$ & $0(0.0 \%)$ & $0(0.0 \%)$ & $0(0.0 \%)$ & $5(0.1 \%)$ \\
\hline Total & $133(100 \%)$ & $136(100 \%)$ & $108(100 \%)$ & $108(100 \%)$ & $87(100 \%)$ & $572(100 \%)$ & $9,893(100 \%)$ \\
\hline \multicolumn{8}{|l|}{ Marital status } \\
\hline Married & $39(29.3 \%)$ & $34(25.0 \%)$ & $32(29.6 \%)$ & $30(27.8 \%)$ & $27(31.0 \%)$ & $162(28.3 \%)$ & $3,749(37.9 \%)$ \\
\hline Unmarried & $48(36.1 \%)$ & $56(41.2 \%)$ & $47(43.5 \%)$ & $49(45.4 \%)$ & $38(43.7 \%)$ & $238(41.6 \%)$ & $3,234(32.7 \%)$ \\
\hline Separated & $3(2.3 \%)$ & $6(4.4 \%)$ & $1(0.9 \%)$ & $0(0.0 \%)$ & $1(1.1 \%)$ & $11(1.9 \%)$ & $335(3.4 \%)$ \\
\hline Divorced & $16(12.0 \%)$ & $18(13.2 \%)$ & $16(14.8 \%)$ & $11(10.2 \%)$ & $5(5.7 \%)$ & $66(11.5 \%)$ & $1,283(13.0 \%)$ \\
\hline Widowed & $5(3.8 \%)$ & $8(5.9 \%)$ & $6(5.6 \%)$ & $4(3.7 \%)$ & $3(3.4 \%)$ & $26(4.5 \%)$ & $621(6.3 \%)$ \\
\hline Unknown & $22(16.5 \%)$ & $14(10.3 \%)$ & $6(5.6 \%)$ & $14(13.0 \%)$ & $13(14.9 \%)$ & $69(12.1 \%)$ & $671(6.8 \%)$ \\
\hline Total & $133(100 \%)$ & $136(100 \%)$ & $108(100 \%)$ & $108(100 \%)$ & $87(100 \%)$ & $572(100 \%)$ & $9,893(100 \%)$ \\
\hline Living alone & $48(36.1 \%)$ & $46(33.8 \%)$ & $37(34.3 \%)$ & $33(30.6 \%)$ & $22(25.3 \%)$ & $186(32.5 \%)$ & $2,754(27.8 \%)$ \\
\hline \multicolumn{8}{|l|}{ Employment status } \\
\hline Employed & $51(38.3 \%)$ & $49(36.0 \%)$ & $38(35.2 \%)$ & $34(31.5 \%)$ & $29(33.3 \%)$ & $201(35.1 \%)$ & $2,225(22.5 \%)$ \\
\hline Self-employed & $11(8.3 \%)$ & $12(8.8 \%)$ & $9(8.3 \%)$ & $13(12.0 \%)$ & $10(11.5 \%)$ & $55(9.6 \%)$ & $956(9.7 \%)$ \\
\hline Housewife & $8(6.0 \%)$ & $8(5.9 \%)$ & $10(9.3 \%)$ & $7(6.5 \%)$ & $4(4.6 \%)$ & $37(6.5 \%)$ & $505(5.1 \%)$ \\
\hline Student & $4(3.0 \%)$ & $8(5.9 \%)$ & $6(5.6 \%)$ & $7(6.5 \%)$ & $5(5.7 \%)$ & $30(5.2 \%)$ & $433(4.4 \%)$ \\
\hline Unemployed & $26(19.5 \%)$ & $34(25.0 \%)$ & $19(17.6 \%)$ & $27(25.0 \%)$ & $17(19.5 \%)$ & $123(21.5 \%)$ & $1,676(16.9 \%)$ \\
\hline Economic inactive & $23(17.3 \%)$ & $17(12.5 \%)$ & $13(12.0 \%)$ & $10(9.3 \%)$ & $13(14.9 \%)$ & $76(13.3 \%)$ & $3,414(34.5 \%)$ \\
\hline Military service & $0(0.0 \%)$ & $0(0.0 \%)$ & $0(0.0 \%)$ & $0(0.0 \%)$ & $0(0.0 \%)$ & $0(0.0 \%)$ & $25(0.3 \%)$ \\
\hline others & $2(1.5 \%)$ & $0(0.0 \%)$ & $2(1.9 \%)$ & $0(0.0 \%)$ & $2(2.3 \%)$ & $6(1.0 \%)$ & $66(0.7 \%)$ \\
\hline Unknown & $8(6.0 \%)$ & $8(5.9 \%)$ & $11(10.2 \%)$ & $10(9.3 \%)$ & $7(8.0 \%)$ & $44(7.7 \%)$ & $593(6.0 \%)$ \\
\hline Total & $133(100 \%)$ & $136(100 \%)$ & $108(100 \%)$ & $108(100 \%)$ & $87(100 \%)$ & $572(100 \%)$ & $9,893(100 \%)$ \\
\hline
\end{tabular}


those seen in Seoul. For example, there was more jumping and gas poisoning compared to the most common method of hanging in District A. These results can help to set different policies and directions to prevent suicide by region.

\section{Characteristics of suicide victims by regional group}

There are many ways to prevent suicide. According to Zalsman's short communication, ${ }^{4}$ suicide prevention requires evidence-based strategies, and Zalsman's 10-year systematic re- view $^{30}$ said that a single strategy is insufficient and a cooperative strategy is needed. Therefore, to show the characteristics of suicide victims based on evidence, we implemented three strategies for various approaches. We also took three approaches to provide characteristics of suicide victims for locally customized suicide prevention projects. First, we focused on areas where both suicide rates and absolute number of suicides were high. Second, we tried to identify characteristics of each region that might have been distinct from other regions. Third, this study

Table 3. Locations, methods and causes of suicide victims in District $A$

\begin{tabular}{|c|c|c|c|c|c|c|c|}
\hline & \multicolumn{6}{|c|}{ District A } & \multirow{2}{*}{$\frac{\text { Seoul }}{\text { Total of Seoul }}$} \\
\hline & 2013 & 2014 & 2015 & 2016 & 2017 & $\begin{array}{c}\text { Total of } \\
\text { district A }\end{array}$ & \\
\hline Number & $133(100 \%)$ & $136(100 \%)$ & $108(100 \%)$ & $108(100 \%)$ & $87(100 \%)$ & $572(100 \%)$ & $9,893(100 \%)$ \\
\hline \multicolumn{8}{|l|}{ Find location } \\
\hline Home & $90(67.7 \%)$ & $87(64.0 \%)$ & $67(62.0 \%)$ & $69(63.9 \%)$ & $41(47.1 \%)$ & $354(61.9 \%)$ & $5,860(59.2 \%)$ \\
\hline Public place & $25(18.8 \%)$ & $27(19.9 \%)$ & $24(22.2 \%)$ & $22(20.4 \%)$ & $23(26.4 \%)$ & $121(21.2 \%)$ & $2,731(27.6 \%)$ \\
\hline School/work place & $5(3.8 \%)$ & $9(6.6 \%)$ & $2(1.9 \%)$ & $4(3.7 \%)$ & $7(8.0 \%)$ & $27(4.7 \%)$ & $286(2.9 \%)$ \\
\hline Accommodations & $5(3.8 \%)$ & $8(5.9 \%)$ & $9(8.3 \%)$ & $1(0.9 \%)$ & $7(8.0 \%)$ & $30(5.2 \%)$ & $414(4.2 \%)$ \\
\hline Suburbs/hill & $1(0.8 \%)$ & $0(0.0 \%)$ & $1(0.9 \%)$ & $3(2.8 \%)$ & $0(0.0 \%)$ & $5(0.9 \%)$ & $276(2.8 \%)$ \\
\hline Hospital & $0(0.0 \%)$ & $0(0.0 \%)$ & $0(0.0 \%)$ & $1(0.9 \%)$ & $0(0.0 \%)$ & $1(0.2 \%)$ & $100(1.0 \%)$ \\
\hline Relatives' home & $0(0.0 \%)$ & $2(1.5 \%)$ & $1(0.9 \%)$ & $2(1.9 \%)$ & $3(3.4 \%)$ & $8(1.4 \%)$ & $90(0.9 \%)$ \\
\hline Acquaintances' home & $5(3.8 \%)$ & $2(1.5 \%)$ & $4(3.7 \%)$ & $4(3.7 \%)$ & $1(1.1 \%)$ & $16(2.8 \%)$ & $73(0.7 \%)$ \\
\hline Others & $2(1.5 \%)$ & $1(0.7 \%)$ & $0(0.0 \%)$ & $2(1.9 \%)$ & $5(5.7 \%)$ & $10(1.7 \%)$ & $63(0.6 \%)$ \\
\hline Total & $133(100 \%)$ & $136(100 \%)$ & $108(100 \%)$ & $108(100 \%)$ & $87(100 \%)$ & $572(100 \%)$ & $9,893(100 \%)$ \\
\hline \multicolumn{8}{|l|}{ Method of suicide } \\
\hline Hanging & $74(55.6 \%)$ & $83(61.0 \%)$ & $65(60.2 \%)$ & $67(62.0 \%)$ & $45(51.7 \%)$ & $334(58.4 \%)$ & $5,620(56.8 \%)$ \\
\hline Gas poisoning & $18(13.5 \%)$ & $14(10.3 \%)$ & $14(13.0 \%)$ & $6(5.6 \%)$ & $10(11.5 \%)$ & $62(10.8 \%)$ & $1,105(11.2 \%)$ \\
\hline Pesticide poisoning & $2(1.5 \%)$ & $1(0.7 \%)$ & $0(0.0 \%)$ & $0(0.0 \%)$ & $1(1.1 \%)$ & $4(0.7 \%)$ & $172(1.7 \%)$ \\
\hline Jumping & $28(21.1 \%)$ & $26(19.1 \%)$ & $27(25.0 \%)$ & $25(23.1 \%)$ & $24(27.6 \%)$ & $130(22.7 \%)$ & $1,977(20.0 \%)$ \\
\hline Drug poisoning & $7(5.3 \%)$ & $4(2.9 \%)$ & $1(0.9 \%)$ & $4(3.7 \%)$ & $1(1.1 \%)$ & $17(3.0 \%)$ & $220(2.2 \%)$ \\
\hline Drowning & $1(0.8 \%)$ & $3(2.2 \%)$ & $0(0.0 \%)$ & $2(1.9 \%)$ & $4(4.6 \%)$ & $10(1.7 \%)$ & $424(4.3 \%)$ \\
\hline Self-harm & $2(1.5 \%)$ & $3(2.2 \%)$ & $1(0.9 \%)$ & $3(2.8 \%)$ & $2(2.3 \%)$ & $11(1.9 \%)$ & $204(2.1 \%)$ \\
\hline Others & $1(0.8 \%)$ & $2(1.5 \%)$ & $0(0.0 \%)$ & $1(0.9 \%)$ & $0(0.0 \%)$ & $4(0.7 \%)$ & $161(1.6 \%)$ \\
\hline Unknown & $0(0.0 \%)$ & $0(0.0 \%)$ & $0(0.0 \%)$ & $0(0.0 \%)$ & $0(0.0 \%)$ & $0(0.0 \%)$ & $10(0.1 \%)$ \\
\hline Total & $133(100 \%)$ & $136(100 \%)$ & $108(100 \%)$ & $108(100 \%)$ & $87(100 \%)$ & $572(100 \%)$ & $9,893(100 \%)$ \\
\hline \multicolumn{8}{|l|}{ Main cause (problem) } \\
\hline Occupational & $9(6.8 \%)$ & $10(7.4 \%)$ & $6(5.6 \%)$ & $11(10.2 \%)$ & $12(13.8 \%)$ & $48(8.4 \%)$ & $513(5.2 \%)$ \\
\hline Economic & $30(22.6 \%)$ & $35(25.7 \%)$ & $21(19.4 \%)$ & $21(19.4 \%)$ & $25(28.7 \%)$ & $132(23.1 \%)$ & $1,922(19.4 \%)$ \\
\hline Family-related & $10(7.5 \%)$ & $5(3.7 \%)$ & $10(9.3 \%)$ & $5(4.6 \%)$ & $3(3.4 \%)$ & $33(5.8 \%)$ & $871(8.8 \%)$ \\
\hline Interpersonal & $10(7.5 \%)$ & $8(5.9 \%)$ & $7(6.5 \%)$ & $4(3.7 \%)$ & $3(3.4 \%)$ & $32(5.6 \%)$ & $463(4.7 \%)$ \\
\hline Physical health & $10(7.5 \%)$ & $9(6.6 \%)$ & $12(11.1 \%)$ & $10(9.3 \%)$ & $7(8.0 \%)$ & $48(8.4 \%)$ & 1,687 (17.1\%) \\
\hline Mental health & $59(44.4 \%)$ & $65(47.8 \%)$ & $41(38.0 \%)$ & $52(9.3 \%)$ & $32(36.8 \%)$ & $249(43.5 \%)$ & $3,910(39.5 \%)$ \\
\hline Others & $2(1.5 \%)$ & $1(0.7 \%)$ & $3(2.8 \%)$ & $1(0.9 \%)$ & $3(3.4 \%)$ & $10(1.7 \%)$ & $134(1.4 \%)$ \\
\hline Unknown & $3(2.3 \%)$ & $3(2.2 \%)$ & $8(7.4 \%)$ & $4(3.7 \%)$ & $2(2.3 \%)$ & $20(3.5 \%)$ & $393(4.0 \%)$ \\
\hline Total & $133(100 \%)$ & $136(100 \%)$ & $108(100 \%)$ & $108(100 \%)$ & $87(100 \%)$ & $572(100 \%)$ & $9,893(100 \%)$ \\
\hline
\end{tabular}


analyzed characteristics of suicide victims in local residents that more closely reflected the characteristics of the region.

\section{The suicide rate and the number of suicide victims}

The suicide rate and the number of suicides are closely related. However, the suicide rate per 100,000 people and the number of suicide deaths may always not match. The suicide rate per 100,000 people is necessary for assessing a change or comparing suicide rates between regions, and the number of suicide victims is important to more actively select places in a region where suicide prevention is necessary. The number of suicides and suicide rates help local suicide prevention practitioners to be more effective in preventing suicide (Figure 2).

\section{Centralized index}

We sought to identify the characteristics of suicide victims in the region through five factors, including the locations, methods, and main causes of suicide, life cycle, and solitary life. Our examination was designed to help prevent suicide locally by determining the characteristics of local suicide victims. Therefore, we developed and applied the Centralized Index (CI) to compare regional characteristics in more detail. The $\mathrm{CI}$ is constructed as an indicator of the relative centralization tendency of the target value among five particular factors such as the Gini coefficient and entropy coefficient. This allowed us to analyze the relative level of the region of the re- sults of the variables. According to Table 3 , suicide is middleaged men with mental health problems often commit suicide by hanging themselves in their homes. However, when CI is applied, there are cases where the different characteristics are shown for each district in the region.

Figure 3 illustrates the characteristics of a particular district in the region. Suicide victims in District A were mainly young women, and most were solitary people who lived alone. In the case of suicide victims in this district, the suicide prevention target can be narrowed because the characteristics differ from those of the norm. A clear understanding of characteristics of suicide victims in the region will thus lead to a more effective reduction of suicide rates.

\section{Characteristics of suicide victims as regional residents}

All suicides do not happen where people live. Some victims end their lives in their homes, and others travel far away to commit suicide. If you examine the characteristics of a suicide victim in a particular district, the victim may not be a resident of the district. To prevent localized suicides, it is important to distinguish the characteristics of suicide victims between those who live in the district and those who have committed suicide in other districts. Figure 4 provides a reflection of the characteristics of both suicide victims living in the district and those who do not. This result can explain the characteristics of people who come in from outside and commit suicide in the dis-

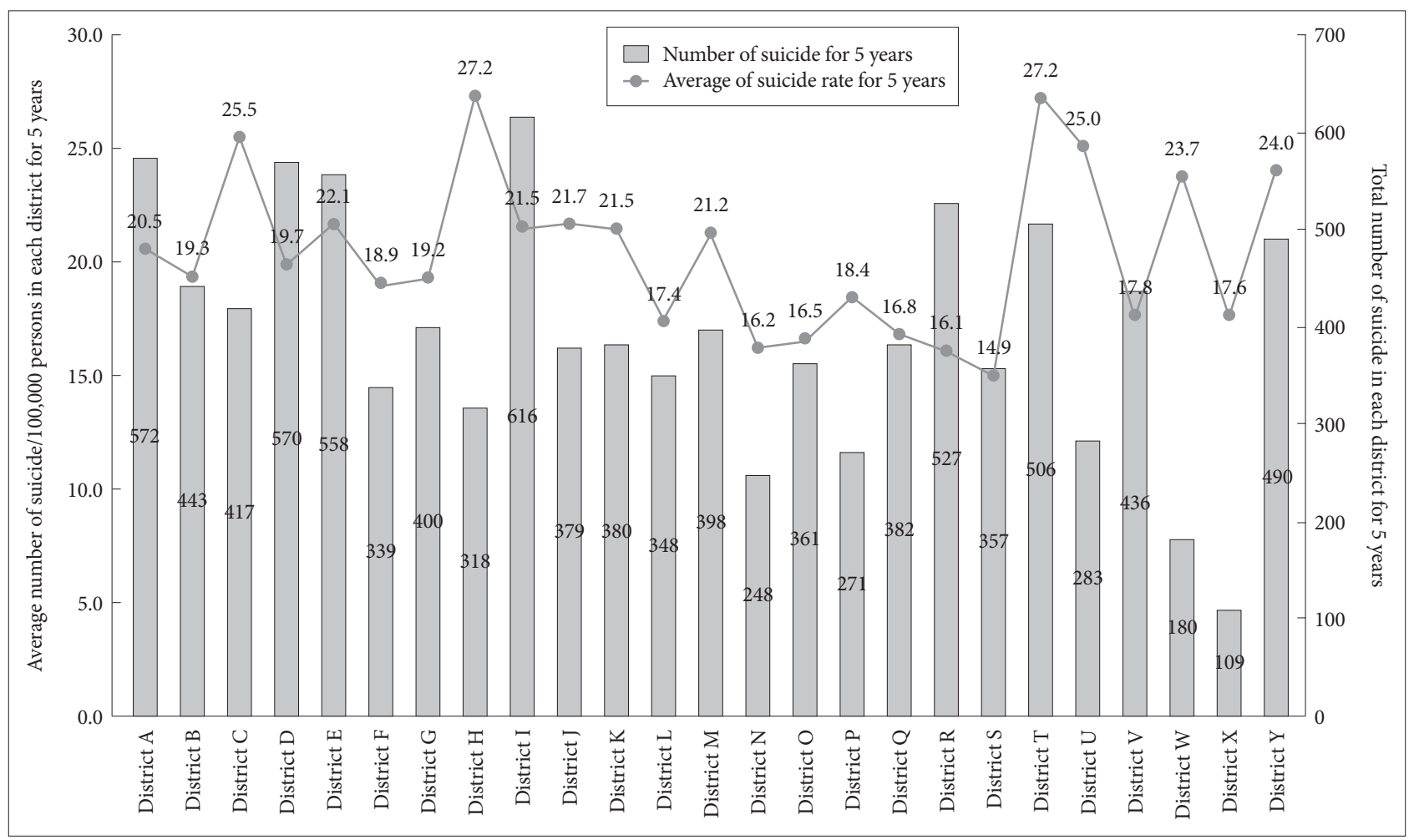

Figure 2. The suicide rate and the number of suicide victims in the region. 
trict, which can help to prevent this type of suicide.

\section{Relation between suicide and age group}

Table 4 shows age-specific differences between psychiatric/ physical disorders (Supplementary Table 1 in the online-only Data Supplement) and suicide of all suicide victims in Seoul

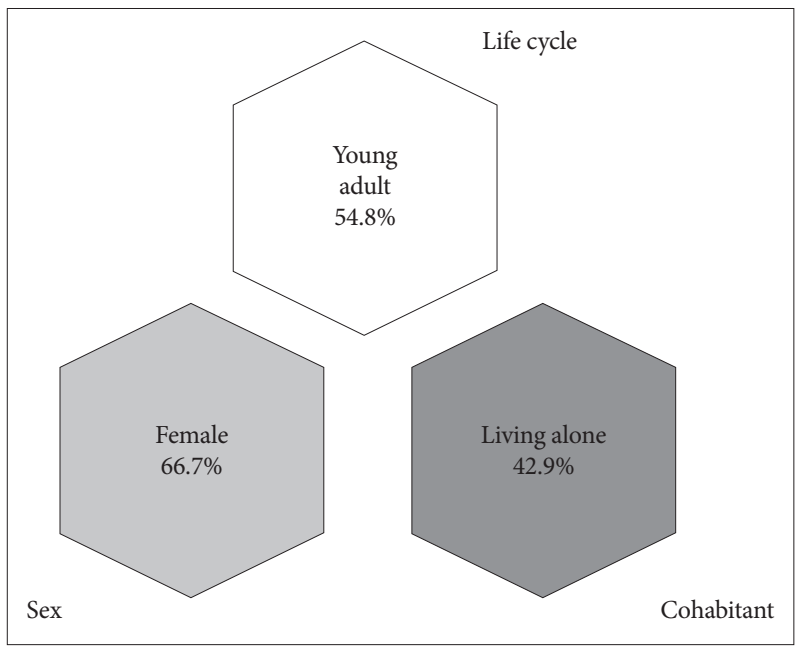

Figure 3. Centralized Index in the region. over five years. We performed a nested case-control study to see the differences in the disorders associated with suicide between suicide victims and the general population in Seoul.

After adjusting for sex, economic status, disability, and all covariates listed in each age group, there were marked differences in the OR associated with suicide according to each age group. In the age group less than 19 years old, depression [adjusted OR $(\mathrm{aOR})=4.38,95 \%$ CI: $2.67-7.28]$ showed the strongest association with suicide. Schizophrenia showed the highest association with suicide in three age groups: $20-34$ years $(\mathrm{aOR}=7.46,95.05 \%$ CI: 5.86-9.51), 35-49 years $(\mathrm{aOR}=6.13$, $95 \%$ CI: $5.05-7.45)$ and $50-65$ years (aOR=3.86, 95\% CI: $3.1^{-}$ 4.8). For the age group of more than 65 years, alcohol use disorder ( $\mathrm{aOR}=2.34,95 \%$ CI: 1.82-2.99) showed the strongest association with suicide. As shown in Table 4, schizophrenia showed high associations with risk of suicide for age groups of $20-34,35-49$, and $50-65$ years.

These results indicate that associations of psychiatric/physical disorders with suicide are different among age groups in South Korea. Therefore, the Seoul Metropolitan Government has become more aware of what to watch for in order to prevent suicide in each age group.

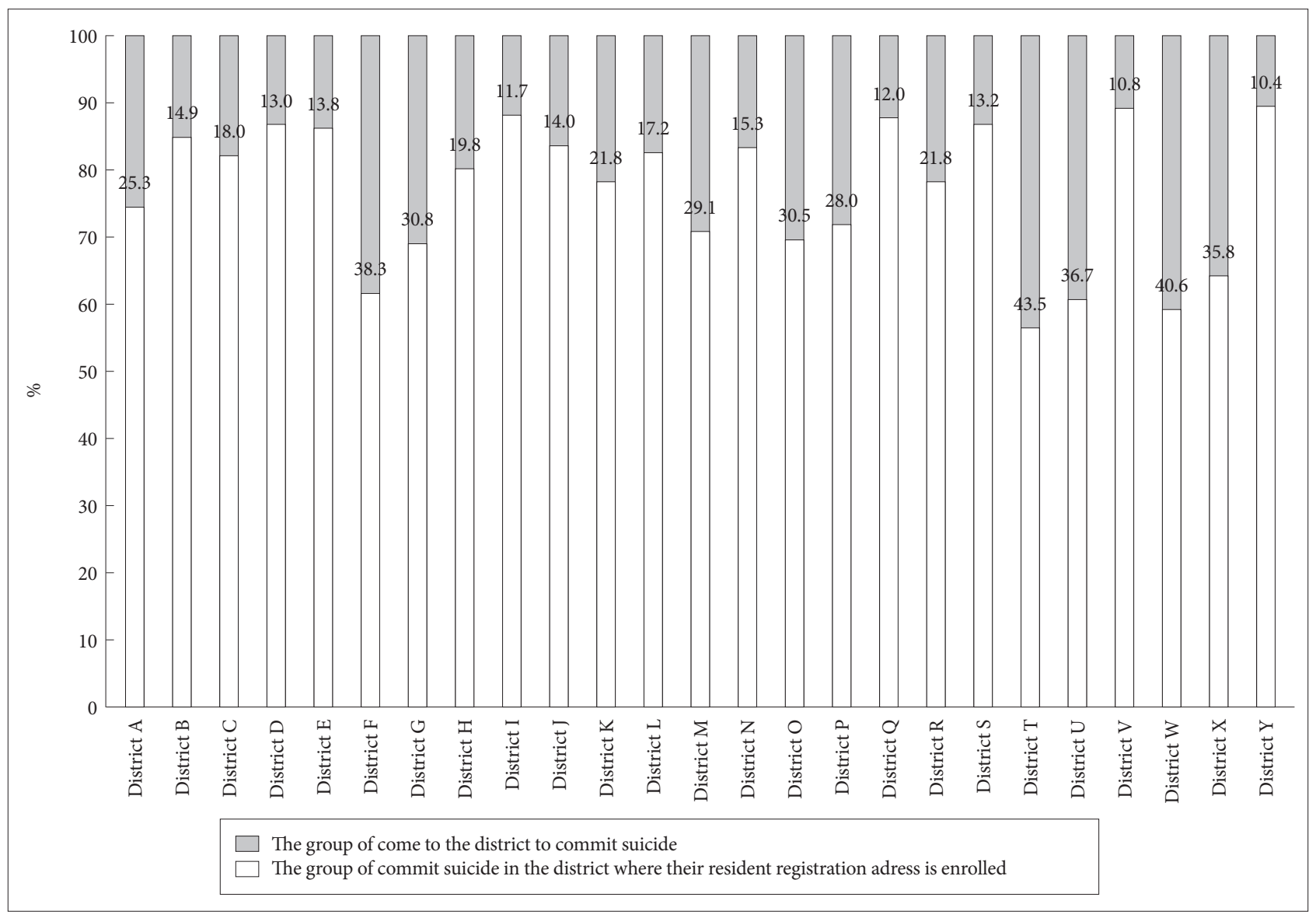

Figure 4. Characteristics of suicide victims as regional residents. 
Table 4. Age differences in risks of suicide by each ICD-10 disorder in the police investigation report from 2013 to 2017

\begin{tabular}{|c|c|c|c|c|c|}
\hline \multirow{2}{*}{ Disorders } & \multicolumn{5}{|c|}{$\mathrm{aORs}^{\mathrm{a}}(95 \% \mathrm{CI})$} \\
\hline & $<19$ years & 20-34 years & $35-49$ years & $50-65$ years & $>65$ years \\
\hline \multicolumn{6}{|l|}{ Psychiatric disorders } \\
\hline Dementia & $0.58(0.1-3.33)$ & $2.11(1.29-3.45)$ & $0.88(0.58-1.34)$ & $0.72(0.54-0.97)$ & $0.88(0.78-1)$ \\
\hline Alcohol use disorder & $b_{-}$ & $2.73(1.85-4.04)^{* * * *}$ & $3.95(3.12-5.01)^{* * * *}$ & $3.1(2.56-3.75)^{* * * *}$ & $2.34(1.82-2.99)^{* * * *}$ \\
\hline Schizophrenia & $13.53(4-45.81)^{* *}$ & $7.46(5.86-9.51)^{* * * *}$ & $6.13(5.05-7.45)^{* * * *}$ & $3.86(3.1-4.8)^{* * * *}$ & $1.41(1.06-1.86)$ \\
\hline Bipolar disorder & $13.19(3.09-56.35)^{*}$ & $3.15(2.35-4.22)^{* * * *}$ & $2.5(1.9-3.28)^{* * * *}$ & $3.11(2.35-4.12)^{* * * *}$ & $2.17(1.61-2.92)^{* * * *}$ \\
\hline Depression & $4.38(2.67-7.18)^{* * * *}$ & $3.8(3.3-4.37)^{* * * *}$ & $3.63(3.2-4.12)^{* * * *}$ & $3.57(3.16-4.03)^{* * * *}$ & $2.7(2.43-3)^{* * * *}$ \\
\hline Anxiety disorder & $3.15(1.67-5.95)^{*}$ & $1.73(1.45-2.07)^{* * * *}$ & $1.64(1.41-1.91)^{* * * *}$ & $1.55(1.35-1.78)^{* * * *}$ & $1.52(1.37-1.7)^{* * * *}$ \\
\hline Adjustment disorder & $2.21(1.13-4.31)$ & $1.26(1.01-1.58)$ & $1.44(1.16-1.79)^{*}$ & $1.68(1.36-2.06)^{* * * *}$ & $1.25(1-1.55)$ \\
\hline Somatoform disorder & $1.63(0.56-4.77)$ & $1.16(0.86-1.56)$ & $1.29(1.03-1.63)$ & $1.43(1.18-1.74)^{* *}$ & $1.17(1.01-1.36)$ \\
\hline Sleep disorder & $2.59(1.04-6.47)$ & $3.2(2.71-3.77)^{* * * *}$ & $3.22(2.83-3.66)^{* * * *}$ & $2.75(2.44-3.09)^{* * * *}$ & $2.18(1.97-2.4)^{* * * *}$ \\
\hline Personality disorder & $2.43(0.38-15.54)$ & $1.92(1.27-2.9)$ & $0.85(0.51-1.44)$ & $1.14(0.58-2.23)$ & $0.75(0.31-1.81)$ \\
\hline Mental retardation & $0.78(0.15-4.09)$ & $0.67(0.33-1.34)$ & $0.53(0.21-1.32)$ & $0.5(0.22-1.11)$ & $0.75(0.38-1.5)$ \\
\hline Developmental disorder & $1.12(0.39-3.26)$ & $0.75(0.33-1.73)$ & $1.33(0.45-3.95)$ & $1.84(0.51-6.61)$ & $1.12(0.4-3.14)$ \\
\hline $\begin{array}{l}\text { Childhood/adolescence } \\
\text { disorder }\end{array}$ & $1.17(0.73-1.87)$ & $0.91(0.67-1.25)$ & $0.72(0.34-1.55)$ & $0.4(0.13-1.26)$ & $1.3(0.65-2.63)$ \\
\hline \multicolumn{6}{|l|}{ Physical disorders } \\
\hline Cancer & $0.86(0.44-1.69)$ & $1.02(0.86-1.21)$ & $1.04(0.91-1.17)$ & $1.1(0.99-1.23)$ & $1.39(1.27-1.52)^{* * * *}$ \\
\hline Benign tumor & $1.13(0.69-1.85)$ & $0.87(0.75-1)$ & $0.79(0.71-0.89)^{* *}$ & $0.81(0.73-0.89)^{* *}$ & $0.78(0.71-0.85)^{* * * *}$ \\
\hline Iron deficiency anemia & $0.82(0.36-1.85)$ & $0.9(0.69-1.17)$ & $1.13(0.92-1.38)$ & $1.32(1.07-1.63)$ & $1.26(1.07-1.49)$ \\
\hline $\begin{array}{l}\text { Disorder of the thyroid } \\
\text { gland }\end{array}$ & $0.86(0.54-1.38)$ & $1.05(0.9-1.23)$ & $0.76(0.66-0.87)^{* *}$ & $0.72(0.63-0.83)^{* * *}$ & $0.86(0.76-0.96)$ \\
\hline Diabetes mellitus & $b_{-}$ & $0.88(0.61-1.26)$ & $1.25(1.07-1.47)$ & $1.33(1.2-1.48)^{* * * *}$ & $1(0.91-1.09)$ \\
\hline $\begin{array}{l}\text { Other nutritional } \\
\text { deficiencies }\end{array}$ & $2.64(0.31-22.26)$ & $0.78(0.5-1.23)$ & $1.14(0.81-1.61)$ & $0.84(0.61-1.15)$ & $1.04(0.84-1.3)$ \\
\hline Epilepsy & $0.15(0.03-0.86)$ & $1.06(0.72-1.56)$ & $1.94(1.41-2.68)^{* *}$ & $0.87(0.61-1.22)$ & $1(0.78-1.29)$ \\
\hline Migraine & $0.89(0.44-1.77)$ & $0.96(0.79-1.16)$ & $0.85(0.72-1.01)$ & $0.76(0.65-0.9)^{*}$ & $1.03(0.91-1.17)$ \\
\hline Vascular disease & $2.06(0.14-31.05)$ & $1.79(0.81-3.92)$ & $1.3(0.84-2.03)$ & $0.93(0.7-1.25)$ & $0.98(0.84-1.16)$ \\
\hline Cataract & $0.64(0.12-3.33)$ & $1.05(0.63-1.76)$ & $1(0.73-1.37)$ & $1.02(0.88-1.17)$ & $0.99(0.9-1.09)$ \\
\hline Glaucoma & $0.7(0.24-2.05)$ & $0.8(0.63-1.02)$ & $0.75(0.62-0.91)$ & $0.88(0.76-1.01)$ & $0.9(0.81-1.01)$ \\
\hline $\begin{array}{l}\text { Visual disturbances } \\
\text { and blindness }\end{array}$ & $0.39(0.15-1)$ & $0.86(0.59-1.26)$ & $0.95(0.62-1.43)$ & $0.9(0.65-1.26)$ & $1.04(0.82-1.33)$ \\
\hline Hearing loss & $0.75(0.31-1.85)$ & $1.08(0.86-1.34)$ & $0.77(0.62-0.95)$ & $0.9(0.76-1.07)$ & $1.07(0.96-1.19)$ \\
\hline Hypertensive disease & $1.09(0.24-4.97)$ & $0.66(0.47-0.92)$ & $0.87(0.76-1)$ & $0.99(0.9-1.09)$ & $1.08(0.98-1.2)$ \\
\hline Ischemic heart disease & $2.73(0.49-15.09)$ & $0.61(0.37-1.02)$ & $0.77(0.6-1)$ & $0.85(0.73-0.98)$ & $0.89(0.81-0.99)$ \\
\hline Cerebrovascular disease & $b_{-}$ & $1.83(1.08-3.1)$ & $1.66(1.27-2.18)^{* *}$ & $1.28(1.1-1.49)$ & $1.23(1.11-1.36)^{* *}$ \\
\hline $\begin{array}{l}\text { Acute upper respiratory } \\
\text { infection }\end{array}$ & $0.69(0.19-2.53)$ & $0.81(0.68-0.97)$ & $0.71(0.63-0.81)^{* * * *}$ & $0.74(0.66-0.84)^{* * * *}$ & $1.02(0.87-1.21)$ \\
\hline Influenza and pneumonia & $0.94(0.69-1.29)$ & $0.88(0.79-0.98)$ & $0.91(0.83-1)$ & $0.99(0.9-1.08)$ & $0.98(0.89-1.09)$ \\
\hline $\begin{array}{l}\text { Chronic lower respiratory } \\
\text { disease }\end{array}$ & $1.38(1-1.91)$ & $0.9(0.81-1.01)$ & $0.87(0.79-0.95)$ & $0.86(0.78-0.95)$ & $1.05(0.96-1.16)$ \\
\hline $\begin{array}{l}\text { Noninfective enteritis } \\
\text { andcolitis }\end{array}$ & $0.87(0.63-1.19)$ & $0.9(0.81-1.01)$ & $0.85(0.76-0.95)$ & $1.1(0.98-1.23)$ & $1.15(1.04-1.26)$ \\
\hline Other disease of intestine & $1.19(0.87-1.63)$ & $0.89(0.8-0.99)$ & $0.82(0.75-0.91)^{* *}$ & $0.75(0.68-0.83)^{* * * *}$ & $1.02(0.93-1.13)$ \\
\hline Alcoholic liver disease & $b_{-}$ & $1.78(1.22-2.61)$ & $1.53(1.26-1.86)^{* *}$ & $1.31(1.12-1.54)^{*}$ & $0.96(0.78-1.17)$ \\
\hline
\end{tabular}


Table 4. Age differences in risks of suicide by each ICD-10 disorder in the police investigation report from 2013 to 2017 (continued)

\begin{tabular}{lccccc}
\hline \multirow{2}{*}{ Disorders } & \multicolumn{5}{c}{ aORs $^{\mathrm{a}}$ (95\% CI) } \\
\cline { 2 - 6 } & \multicolumn{1}{c}{$<$ 19 years } & $20-34$ years & $35-49$ years & $50-65$ years & $>65$ years \\
\hline Atopic dermatitis & $1.09(0.78-1.51)$ & $0.91(0.79-1.06)$ & $0.89(0.75-1.05)$ & $0.95(0.79-1.14)$ & $0.84(0.72-0.98)$ \\
Psoriasis & $0.85(0.19-3.86)$ & $1(0.7-1.43)$ & $1(0.76-1.33)$ & $1.17(0.91-1.51)$ & $1.19(0.95-1.48)$ \\
Arthropathies & $0.97(0.68-1.38)$ & $0.74(0.66-0.82)^{* * * *}$ & $0.97(0.89-1.07)$ & $0.95(0.86-1.04)$ & $0.88(0.79-0.99)$ \\
Renal failure & $\mathrm{b}$ - & $2.18(0.99-4.78)$ & $1.68(1-2.83)$ & $2.02(1.51-2.69)^{* * * *}$ & $1.03(0.85-1.25)$ \\
Urolithiasis & $1.08(0.13-9.32)$ & $1.23(0.91-1.68)$ & $0.76(0.62-0.94)$ & $0.87(0.72-1.04)$ & $0.82(0.68-0.99)$ \\
Congenital disease & $0.6(0.25-1.45)$ & $1.05(0.79-1.4)$ & $0.71(0.47-1.1)$ & $0.96(0.66-1.39)$ & $0.88(0.64-1.22)$ \\
Congenital malformation & $2.59(0.26-25.72)$ & $0.41(0.15-1.16)$ & $2.88(1.17-7.11)$ & $0.56(0.16-2.04)$ & $0.85(0.33-2.15)$ \\
$\quad$ of the circulatory system & & & & $1.49(1.14-1.96)$ & $1.1(0.86-1.42)$ \\
Multiple body injury & $1.73(0.89-3.34)$ & $1.57(1.21-2.04)^{*}$ & $1.26(0.96-1.66)$ & $1.49)$ \\
Effects of foreign body & $0.76(0.47-1.23)$ & $0.84(0.71-1)$ & $0.96(0.84-1.09)$ & $0.89(0.8-1)$ & $1.06(0.95-1.18)$ \\
Burns and corrosions & $1.06(0.64-1.75)$ & $1.31(1.12-1.54)^{*}$ & $1.04(0.89-1.23)$ & $1.16(1-1.36)$ & $1.23(1.06-1.43)$ \\
\hline
\end{tabular}

Significance levels: ${ }^{*} \mathrm{p}<0.05,{ }^{* *} \mathrm{p}<0.01,{ }^{* * *} \mathrm{p}<0.001,{ }^{* * * *} \mathrm{p}<0.0001 .{ }^{\mathrm{a}}$ Model adjusted for income level, disability, and all covariates listed, statistical significance for aORs was calculated after Holm-Bonferroni correction for all covariates included, baOR incalculable due to no case of each disorder in the control group. NHIS-NSC: National Health Insurance Service-National Sample Cohort, aORs: adjusted odds ratios, CI: confidential interval

\section{DISCUSSION}

There are many reports ${ }^{1,31-37}$ that have studied and analyzed the causes of suicide in different countries. However, to the best of our knowledge, this is the first study to examine almost all suicide victims nationwide in South Korea, and it is the first paper to study the disease characteristics of suicide victims in more depth by matching national data from the NHID. The main findings of this study are as follows: 1) from 2013 to 2017 , nearly all of the nation's suicide victims have been studied, 2) in addition to the location and method of suicides, the association with certain diseases was also studied, and 3) suicide victims from each district may have different characteristics, and therefore different approaches are needed to prevent suicide.

The most specific finding of this study is that the characteristics of people who died by regional suicide are different. There have been many articles ${ }^{11,38-49}$ that reported risk factors of suicide. As mentioned in these papers, numerous factors contribute to suicide. Social, cultural, psychological, and other medical factors are organically related to committing suicide. Based on these common risk factors, a policy to prevent suicide in a community can be implemented. However, if the policy is implemented to reflect the characteristics of suicide victims in each region, it could shorten the time that it takes to reduce the suicide rate. Our study was comprised of two parts to investigate the characteristics of suicide victims: 1 ) a pilot study and 2) an article that examined the link between suicide victims and diseases in the 1,000,000 sample cohort in the NHID. Through these two parts, this study developed and implemented suicide research methods.
This method of suicide research examines the demographic characteristics and locations, methods and main causes of nearly all suicides in the past five years, from 2013 to 2017. Besides, as mentioned in the results, the CI shows the local characteristics better, which should be mainly focused on by specific region. This is because the $\mathrm{CI}$ explains the degree of bias of each factor among the five aspects of suicidal deaths: locations, methods, and main causes of suicide, life cycle, and solitary life. The results obtained through the CI help to better understand the characteristics of suicide victims in the region and provide a clearer picture of the factors that reduce suicide. Furthermore, by matching the ID number of the suicide victim and NHIS data before death, we can study psychiatric and physical disorders that are highly correlated with suicide. A more in-depth analysis of suicide victims by region can provide a different perspective to the Regional Mental Health Promotion Center. Information on districts where the number of suicides is high and studies of specific factors beyond common suicide factors based on the results will contribute to reducing suicide mortality.

Despite the many advantages of this study, it has several limitations. First, the number of suicide victims in this study does not include all suicides over the five years from 2013 to 2017. Only a very small proportion of suicide victims are missing from the data, such as a person who died of suicide at sea, Koreans who died overseas, and so on. A comparison of the number of suicide victims in the Seoul area after the investigation showed that there was a difference of about five percent between our investigation and the data of the Korea National Statistical Office. Although there are few differences, cooperation with the National Statistical Office will be needed in the 
future to better characterize suicide victims in South Korea. Second, the interpretation of economic problems among the analysis of the main cause of suicide death can be somewhat ambiguous. According to the results, the main causes of suicide deaths were mental health problems, physical health problems and economic problems. Because we studied the health data of the suicide victim's ID number, the link between suicide and medical disorders could be studied more clearly based on the NHID. However, it is difficult to pinpoint the relationship between economic problems and suicide because we only know the income distribution of suicide victims in the NHID. To complement these data, it may be necessary to link information about changes in employment status or debt before the death of a suicide victim in the future. Lastly, it is difficult to verify the effects of suicide prevention through our results because this is a retrospective study. Based on the design of this research, if the results permit implementation of the local suicide prevention project our findings may contribute to reducing suicide rates. To assess the efficiency of regional suicide rate change and regional customized suicide prevention policy, the study of suicide victims by region needs to be continued prospectively every year.

In conclusion, suicide prevention policy should be implemented by analyzing the various causes of suicide in each region, and continuing research is needed to verify its effectiveness in the future.

\section{Supplementary Materials}

The online-only Data Supplement is available with this article at https://doi.org/10.30773/pi.2019.07.14.

\section{Acknowledgments}

This study was mainly supported by the Korea Ministry of Health and Welfare. This study was conducted by the research and analysis team (Minha Gwak, MiHwa Kim, Sunghun Kim, KeunHue Sung, Deukkweon You, Jeongyoon Lee, Seona Lee, Daeun Lee, Soonju Lee, Eunjeong Cho and Hyein Hong) and investigators at Korea Psychological Autopsy Center (KPAC) (Director: Hong Jin Jeon, MD, PhD). The KPAC is operated by the Research \& Business Foundation of Sungkyunkwan University on commission of the Korea Ministry of Health and Welfare from January 2016. This research was partially supported by a grant of the Korea Mental Health R\&D Project, funded by the Ministry of Health \& Welfare, Republic of Korea (grant number: HL19C0001).

\section{Conflicts of Interest}

The authors have no potential conflicts of interest to disclose.

\section{Author Contributions}

Conceptualization: Eun Jin Na, Jinhwa Choi, Hong Jin Jeon. Data curation: Eun Jin Na, Jinhwa Choi, Dajung Kim, Heeyoun Kwon, Yejin Lee, Hong Jin Jeon. Formal analysis: Eun Jin Na, Jinhwa Choi, Hong Jin Jeon. Funding acquisition: Eun Jin Na, Hong Jin Jeon. Investigation: Jinhwa Choi, Dajung Kim, Heeyoun Kwon, Yejin Lee. Methodology: Eun Jin Na, Jinhwa Choi, Hong Jin Jeon. Project administration: Eun Jin Na, Jinhwa Choi, Dajung Kim, Heeyoun Kwon, Yejin Lee, Hong Jin Jeon. Resources: Eun Jin Na, Jinhwa Choi, Dajung Kim, Heeyoun Kwon, Yejin Lee, Hong Jin Jeon. Soft- ware: Eun Jin Na, Jinhwa Choi, Hong Jin Jeon. Supervision: Gusang Lee, Maurizio Fava, David Mischoulon, Jihoon Jang. Validation: Eun Jin Na, Gusang Lee, Maurizio Fava, David Mischoulon, Jihoon Jang, Hong Jin Jeon. Visualization: Jinhwa Choi, Dajung Kim, Heeyoun Kwon, Yejin Lee. Writing_original draft: Eun Jin Na. Writing — review \& editing: Hong Jin Jeon.

\section{ORCID iDs}

$\begin{array}{ll}\text { Hong Jin Jeon } & \text { https://orcid.org/0000-0002-6126-542X } \\ \text { Eun Jin Na } & \text { https://orcid.org/0000-0002-1111-0446 }\end{array}$

\section{REFERENCES}

1. Lee SU, Park JI, Lee S, Oh IH, Choi JM, Oh CM. Changing trends in suicide rates in South Korea from 1993 to 2016: a descriptive study. BMJ Open 2018;8:e023144.

2. Ha K. Can a suicide prevention law decrease the suicide rate in Korea? J Korean Med Assoc 2011;54:792-794.

3. Hawton K, Saunders KE. Psychiatric service development and suicide. Lancet 2009;373:99-100.

4. Zalsman G, Hawton K, Wasserman D, van Heeringen K, Arensman E, Sarchiapone M, et al. Evidence-based national suicide prevention taskforce in Europe: a consensus position paper. Eur Neuropsychopharmacol 2017;27:418-421.

5. Hadlaczky G, Wasserman D, Hoven CW, Mandell DJ, Wasserman C. International Handbook of Suicide Prevention (2nd Ed). In: Rory C, O'Connor, Jane Pirkis, Editors, Suicide Prevention Stratergies: Case Studies from Across the Globe. Oxford: John Wiley \& Sons, 2016, p.556568.

6. Brodsky BS, Spruch-Feiner A, Stanley B. The zero suicide model: applying evidence-based suicide prevention practices to clinical care. Front Psychiatry 2018;9:33.

7. Beautrais A, Fergusson D, Coggan C, Collings C, Doughty C, Ellis P, et al. Effective strategies for suicide prevention in New Zealand: a review of the evidence. NZ Med J 2007;120:U2459.

8. Mann JJ, Apter A, Bertolote J, Beautrais A, Currier D, Haas A, et al. Suicide prevention strategies: a systematic review. JAMA 2005;294:20642074.

9. Van der Feltz-Cornelis CM, Sarchiapone M, Postuvan V, Volker D, Roskar S, Grum AT, et al. Best practice elements of multilevel suicide prevention strategies. Crisis 2011;32:319-333.

10. World Health Organization. Public Health Action for the Prevention of Suicide: a Framework. Geneva: WHO Press; 2012.

11. Kim MD, Hong SC, Lee SY, Kwak YS, Lee CI, Hwang SW, et al. Suicide risk in relation to social class: a national register-based study of adult suicides in Korea, 1999-2001. Int J Soc Psychiatry 2006;52:138-151.

12. Kwon JW, Chun H, Cho SI. A closer look at the increase in suicide rates in South Korea from 1986-2005. BMC Public Health 2009;9:72.

13. Kim SW, Yoon JS. Suicide, an urgent health issue in Korea. J Korean Med Sci 2013;28:345-347.

14. Fu KW, Chan $\mathrm{CH}$. A study of the impact of thirteen celebrity suicides on subsequent suicide rates in South Korea from 2005 to 2009. PLoS One 2013;8:e53870.

15. Chan CH, Caine ED, You S, Fu KW, Chang SS, Yip PS. Suicide rates among working-age adults in South Korea before and after the 2008 economic crisis. J Epidemiol Community Health 2014;68:246-252.

16. Park C, Jee YH, Jung KJ. Age-period-cohort analysis of the suicide rate in Korea. J Affect Disord 2016;194:16-20.

17. Lee SY, Hong JS, Espelage DL. An ecological understanding of youth suicide in South Korea. Sch Psychol Int 2010;31:531-546.

18. Ahn E, Shin DW, Cho SI, Park S, Won YJ, Yun YH. Suicide rates and risk factors among Korean cancer patients, 1993-2005. Cancer Epidemiol Biomarkers Prev 2010;19:2097-2105.

19. Im JS, Choi SH, Hong D, Seo HJ, Park S, Hong JP. Proximal risk factors and suicide methods among suicide completers from national suicide mortality data 2004-2006 in Korea. Compr Psychiatry 2011;52:231-237. 
20. Shin KM, Cho SM, Hong CH, Park KS, Shin YM, Lim KY, et al. Suicide among the elderly and associated factors in South Korea. Aging Ment Health 2013;17:109-114.

21. Kim Y, Myung W, Won HH, Shim S, Jeon HJ, Choi J, et al. Association between air pollution and suicide in South Korea: a nationwide study. PLoS One 2015;10:e0117929.

22. Seo JG, Lee JJ, Cho YW, Lee SJ, Kim JE, Moon HJ, et al. Suicidality and its risk factors in Korean people with epilepsy: a MEPSY study. J Clin Neurol 2015;11:32-41.

23. Lee $\mathrm{S}$, Shin A. Association of atopic dermatitis with depressive symptoms and suicidal behaviors among adolescents in Korea: the 2013 Korean Youth Risk Behavior Survey. BMC Psychiatry 2017;17:3.

24. Lee J, Yang J, Lyu J. Suicide among the elderly in Korea: a meta-analysis. Innov Aging 2017;1 (suppl 1):419.

25. Park S, Jang H. Correlations between suicide rates and the prevalence of suicide risk factors among Korean adolescents. Psychiatry Res 2018; 261:143-147.

26. Choi HY, Kim GE, Kong KA, Lee YJ, Lim WJ, Park SH, et al. Psychological and genetic risk factors associated with suicidal behavior in Korean patients with mood disorders. J Affect Disord 2018;235:489-498.

27. Kim B, Lee J, Kim E, Kim SH, Ha K, Kim YS, et al. Sex difference in risk period for completed suicide following prior attempts: Korea National Suicide Survey (KNSS). J Affect Disord 2018;227:861-868.

28. Cheong KS, Choi MH, Cho BM, Yoon TH, Kim CH, Kim YM, et al. Suicide rate differences by sex, age, and urbanicity, and related regional factors in Korea. J Prev Med Public Health 2012;45:70-77.

29. Na KS, Paik JW, Yun MK, Kim HS. Psychological autopsy: review and considerations for future directions in Korea. J Korean Neuropsychiatr Assoc 2015;54:40-48.

30. Zalsman G, Hawton K, Wasserman D, van Heeringen K, Arensman E, Sarchiapone M, et al. Suicide prevention strategies revisited: 10-year systematic review. Lancet Psychiatry 2016;3:646-659.

31. Yang GH, Phililips M, Zhou MG, Wang LJ, Zhang YP, Xu D. Understanding the unique characteristics of suicide in China: national psychological autopsy study. Biomed Environ Sci 2005;18:379-389.

32. Thomas K, Gunnell D. Suicide in England and Wales 1861-2007: a timetrends analysis. Int J Epidemiol 2010;39:1464-1475.

33. Aggarwal S. Suicide in India. Br Med Bull 2015;114: 127-134.

34. Harper S, Charters TJ, Strumpf EC, Galea S, Nandi A. Economic downturns and suicide mortality in the USA, 1980-2010: observational study. Int J Epidemiol 2015;44:956-966.

35. Jeon SY, Reither EN, Masters RK. A population-based analysis of in- creasing rates of suicide mortality in Japan and South Korea, 1985-2010. BMC Public Health 2016;16:356.

36. Chang SS, Cheng Q, Lee ES, Yip PS. Suicide by gassing in Hong Kong 2005-2013: Emerging trends and characteristics of suicide by helium inhalation. J Affect Disord 2016;192:162-166.

37. Dyvesether SM, Nordentoft M, Forman JL, Erlangsen A. Joinpoint regression analysis of suicides in Denmark during 1980-2015. Danish Med J 2018;65. pii: A5477.

38. Roškar S, Podlesek A, Kuzmanić M, Demšar LO, Zaletel M, Marušič A. Suicide risk and its relationship to change in marital status. Crisis 2011; 32:24-30.

39. Yur'yev A, Värnik A, Värnik P, Sisask M, Leppik L. Employment status influences suicide mortality in Europe. Int J Soc Psychiatry 2012;58:6268.

40. Lenzi M, Colucci E, Minas H. Suicide, culture, and society from a crossnational perspective. Cross Cult Res 2012;46:50-71.

41. Kyaga S, Landén M, Boman M, Hultman CM, Långström N, Lichtenstein P. Mental illness, suicide and creativity: 40-year prospective total population study. J Psychiatr Res 2013;47:83-90.

42. Qin P, Webb R, Kapur N, Sørensen HT. Hospitalization for physical illness and risk of subsequent suicide: a population study. J Int Med 2013; 273:48-58.

43. Yuodelis-Flores $\mathrm{C}$, Ries RK. Addiction and suicide: a review. Am J Addict 2015;24:98-104.

44. Bernert RA, Kim JS, Iwata NG, Perlis ML. Sleep disturbances as an evidence-based suicide risk factor. Curr Psychiatry Rep 2015;17:554.

45. Perlis ML, Grandner MA, Brown GK, Basner M, Chakravorty S, Morales $\mathrm{KH}$, et al. Nocturnal wakefulness: a previously unrecognized risk factor for suicide. J Clin Psychiatry 2016;77:e726-e733.

46. Chan MK, Bhatti H, Meader N, Stockton S, Evans J, O'Connor RC, et al. Predicting suicide following self-harm: systematic review of risk factors and risk scales. Br J Psychiatry 2016;209:277-283.

47. Khemiri L, Jokinen J, Runeson B, Jayaram-Lindström N. Suicide risk associated with experience of violence and impulsivity in alcohol dependent patients. Sci Rep 2016;6:19373.

48. Gunnell D, Chang SS. International Handbook of Suicide Prevention (2nd ed). In: Rory C, O'Connor, Jane Pirkis, Editors, Economic Recession, Unemployment, and Suicide. Oxford: John Wiley \& Sons, 2016, p.284-300.

49. Steele IH, Thrower N, Noroian P, Saleh FM. Understanding suicide across the lifespan: a United States perspective of suicide risk factors, assessment \& management. J Forens Sci 2018;63:162-171. 
Supplementary Table 1. ICD-10 disorders and suicide cases during their lifetime

\begin{tabular}{|c|c|}
\hline Disorders & ICD-10 codes \\
\hline \multicolumn{2}{|l|}{ Psychiatric disorders } \\
\hline Dementia & F00-09/G30 \\
\hline Alcohol use disorder & F10 \\
\hline Schizophrenia & F20-29 \\
\hline Bipolar disorder & F30-31 \\
\hline Depression & F32-39 \\
\hline Anxiety disorder & F $40-41$ \\
\hline Adjustment disorder & F43 \\
\hline Somatoform disorder & F45 \\
\hline Sleep disorder & F51/G47 \\
\hline Personality disorder & F60-69 \\
\hline Mental retardation & F70-79 \\
\hline Developmental disorder & F80-89 \\
\hline Childhood and adolescence disorder & F90-98 \\
\hline \multicolumn{2}{|l|}{ Physical disorders } \\
\hline Cancer & C00-D09 \\
\hline Benign tumor & D10-48 \\
\hline Iron deficiency anemia & D50 \\
\hline Disorder of the thyroid gland & E00-07 \\
\hline Diabetes mellitus & E10-14 \\
\hline Other nutritional deficiencies & E50-64 \\
\hline Epilepsy & G40-41 \\
\hline Migraine & G43 \\
\hline Vascular disease & G45-46 \\
\hline Cataract & H25-26 \\
\hline Glaucoma & H40-42 \\
\hline Visual disturbances and blindness & H53-54 \\
\hline Hearing loss & H90-91 \\
\hline Hypertensive disease & $\mathrm{I} 10-15$ \\
\hline Ischemic heart disease & $\mathrm{I} 20-25$ \\
\hline Cerebrovascular disease & I60-69 \\
\hline Acute upper respiratory infection & J00-06 \\
\hline Influenza and pneumonia & J09-18 \\
\hline Chronic lower respiratory disease & $\mathrm{J} 40-47$ \\
\hline Noninfective enteritis and colitis & K50-52 \\
\hline Other diseases of intestines & K55-63 \\
\hline Alcoholic liver disease & K70 \\
\hline Atopic dermatitis & $\mathrm{L} 20$ \\
\hline Psoriasis & $\mathrm{L} 40$ \\
\hline Arthropathies & M00-25 \\
\hline Renal failure & N17-19 \\
\hline Urolithiasis & N20-23 \\
\hline Congenital disease & Q00-99 \\
\hline $\begin{array}{l}\text { Congenital malformation of the circulatory } \\
\text { system }\end{array}$ & Q20-28 \\
\hline Multiple body injury & T00-07 \\
\hline Effects of foreign body & T15-19 \\
\hline Burns and corrosions & T20-32 \\
\hline
\end{tabular}

ICD-10: International Classification of Diseases: Tenth Revisio 